\title{
The Biosynthesis of Polyamines in the Brain of Audiogenic Seizure-Susceptible and -Resistant Deermice
}

\author{
Raffaele Porta, Richard L. Doyle, Stephen B. Tatter, Timothy E. Wilens, \\ Robert A. Schatz, and Otto Z. Sellinger \\ Laboratory of Neurochemistry, Mental Health Research Institute, University of Michigan Medical Center. \\ Ann Arbor, Michigan, U.S.A.
}

\begin{abstract}
The biosynthesis of polyamines was investigated in the brains of the audiogenic seizure-susceptible (SS) mutant and the wild-type, seizure-resistant (SR) deermouse Peromyscus maniculatus bairdii. For this purpose a new, rapid, and economical high pressure liquid chromatography (HPLC) procedure for the quantitation of putrescine, spermidine, and spermine was developed. Benzoyl derivatives of the polyamines, prepared from a crude brain supernatant, were ether extracted and, following removal of the ether, were separated and quantitated by HPLC. The high sensitivity of the method allows quantitation of putrescine in $50 \mathrm{mg}$ and of spermidine and spermine, in as little as 2-2.5 $\mathrm{mg}$, of brain tissue. No differences were found in endogenous levels of the 3 polyamines in brains of SS vs SR deermice. Using $\left[{ }^{14} \mathrm{C}\right.$ ]putrescine as a polyamine precursor, we found the specific radioactivity of spermidine to be lower in the SS than in the SR brains following a $1 \mathrm{~h}$ intraventricular (i.vt.) pulse. No such differences were noted if $\left[3,4{ }^{14} \mathrm{C}\right]$ methionine was used as the polyamine precursor. To test whether the flux of methionine through the transmethylation pathway was also different in SS and SR deermouse brain, we administered $\left[1-{ }^{14} \mathrm{C}\right]$ methionine (i.vt.) $(1 \mathrm{~h}$ pulse $)$. Even though the brains of SS animals contained higher methionine and lower S-adenosyl-L-methionine (AdoMet) levels than the SR brains, the specific radioactivities of methionine and AdoMet were, respectively, lower and higher in SS compared to SR brains. The latter results are in agreement with our previous findings of an accelerated utilization of AdoMet in brains of Swiss-Webster mice following administration of the chemical convulsant $\mathrm{L}$-methionine- $d, l$-sulfoximine (MSO). Taken together, the data suggest that the SS condition, whether genetically determined (as in the SS deermouse) or chemically elicited (as after MSO), correlates positively with higher than normal rates of conversion of methionine to brain AdoMet and leads to an enhanced rate of utilization of AdoMet via the transmethylation pathway. Key Words: Seizure-sensitiveSeizure-resistant-deermice-Brain polyamines--Transmethylation- $S$ adenosyl-L-methionine-HPLC. Porta R. et al. The biosynthesis of polyamines in the brain of audiogenic seizure-susceptible and -resistant deermice. J. Neurochem. 37, 723-729 (1981).
\end{abstract}

Received February 11, 1981; accepted April 8, 1981.

Address correspondence and reprint requests to Otto $\mathrm{Z}$. Sellinger, Mental Health Research Institute, University of Michigan, 205 Washtenaw Place, Ann Arbor, Michigan 48109

Raffaele Porta's present address is Department of Biochemistry, First Medical School, University of Naples, via Costantinopoli 16, 80138 Naples, Italy.
Abbreviations used: AdoHcy, $S$-Adenosyl-L-homocysteine: AdoMet, $S$-adenosyl-1-methionine; HPLC, High pressure liquid chromatography; i.vt.. Intraventricular; MSO, L-Methionined,l-sulfoximine; Pt, Putrescine; Spd, Spermidine: Spm. Spermine; SR, Seizure-resistant; s.r.a., Specific radioactivity: SS, Seizure-susceptible; TCA. Trichloroacetic acid. 
Our past research on the effects of the chemical convulsant $\mathbf{L}$-methionine-d, $l$-sulfoximine (MSO) on cerebral methylation reactions (Schatz and Sellinger, 1975) has revealed lower than normal levels of $S$-adenosyl-L-methionine (AdoMet) in brain after MSO administration. This decrease appears to be the consequence of an MSO-elicited acceleration of the in vivo methylation of a number of cerebral methyl-accepting substances including histamine (Schatz et al., 1978), transfer ribonucleic acids (Salas et al., 1977; Dainat et al., 1978), proteins (Schatz et al., 1981a), and phospholipids (Schatz et al., 1981a). Recently, we also found significant differences in the in vitro activity of brain histamine $N$ (EC 2.1.1.8) and catechol $O$ - (EC 2.1.1.6) methyltransferases (Doyle and Sellinger, 1980) as well as in the in vivo rates of cerebral histamine methylation (Doyle et al., 1981) when comparing the autosomal recessive, audiogenic seizure-sensitive (SS) mutant and the wild-type, seizure resistant (SR) deermouse Peromyscus maniculatus bairdii. On the basis of our overall findings we suggested that methylation may be characteristically elevated in the brains of the SS Peromyscus as well as in the brains of MSO-treated mice.

In addition to its role as the universal methyl donor molecule, AdoMet, in its decarboxylated form, donates its n-propylamino moiety to putrescine $(\mathrm{Pt})$ to form spermidine (Spd) and to $\mathrm{Spd}$ to form spermine (Spm), both Spd and Spm being known to elicit convulsions (Anderson et al., 1975; Sakurada et al., 1975; Shaw, 1979a). It appeared necessary, therefore, to determine whether the flux of methionine through AdoMet and on to Spd and Spm is also altered in the "seizure prone" brain. In light of the recent finding (Antrup and Seiler, 1980) that "the two parts of the polyamine molecule which derive from ornithine (the precursor of putrescine) and methionine have significantly different life spans", we injected SS and SR deermice with $\left[{ }^{14} \mathrm{C}\right]$ methionine or putrescine and determined their respective incorporation into Spd and Spm. We also determined the endogenous levels of Pt, Spd, and Spm in brains of SS and SR deermice. For polyamine determinations we used a new, rapid, sensitive assay procedure which is described in detail below. This new procedure utilizes reverse phase high pressure liquid chromatography (HPLC) to separate the benzoylated derivatives of $\mathrm{Pt}, \mathrm{Spd}$, and Spm (Redmond and Tseng, 1979). The salient advantages of this procedure over the numerous existing ones (Seiler, 1977; Newton and AbdelMonem, 1977; Radhakrishnan et al., 1977; Seiler et al., 1978; Saeki et al., 1978; Kai et al., 1979; Brown et al., 1979; Dresser et al., 1980) are: (1) benzoylation is done directly on the neutralized perchloric acid brain supernatant without any pre-purification; (2) the entire HPLC run requires less than $10 \mathrm{~min}$ for each sample; and (3) no gradient elution is required.

\section{MATERIALS AND METHODS}

\section{Apparatus}

A Waters Model ALC/GPC-204 liquid chromatograph equipped with a Model 6000A high-pressure pump, a U6K loop injector and Model 440 absorbance detector $(254 \mathrm{~nm})$ was used throughout the study. An Omniscribe recorder (Texas Instruments, Austin. Texas) was used to record the chromatographic runs. A prepacked $(30 \times 0.4 \mathrm{~cm}$, i.d.) $\mu$ Bondapak $\mathrm{C} 18$ column (Waters Associates, Milford, Massachusetts) was used to separate the benzoylated polyamines.

\section{Chemicals}

Putrescine diHCl, spermidine triHCl, spermine tet$\mathrm{raHCl}$ and diethylpyrocarbonate were purchased from Sigma Chemical Co. (St. Louis, Missouri). [1,4$\left.{ }^{14} \mathrm{C}\right] \mathrm{Putrescine}$ diHCl $(122 \mathrm{mCi} / \mathrm{mmol}),\left[{ }^{14} \mathrm{C}\right]$ spermidine triHCl $(122 \mathrm{mCi} / \mathrm{mmol}),\left[{ }^{4} \mathrm{C}\right]$ spermine tetraHCl $(122$ $\mathrm{mCi} / \mathrm{mmol})$ and $\mathrm{L}-\left[1{ }^{-14} \mathrm{C}\right]$ methionine $(59 \mathrm{mCi} / \mathrm{mmol})$ were obtained from Amersham/Searle (Arlington Heights, I!linois).

$\mathrm{L}-\left[3,4{ }^{14} \mathrm{C}\right]$ Methionine $(49 \mathrm{mCi} / \mathrm{mmol})$ was from $\mathrm{Re}$ search Products International Corp. (Elk Grove Village, Illinois) $\mathrm{L}-\mathrm{f}^{3} \mathrm{H}$-methyl]-Methionine $(1 \mathrm{Ci} / \mathrm{mmol})$ was from ICN Pharmaceuticals (Irvine, California), and $\left[{ }^{14} \mathrm{C}\right] \mathrm{Ado}-$ Met $(57 \mathrm{mCi} / \mathrm{mmol})$ and $\left[88^{-14} \mathrm{C}\right]$ adenosine $(54 \mathrm{mCi} / \mathrm{mmol})$ were from New England Nuclear (Boston, Massachusetts). $S$-Adenosyl-L-methionine disulfate di-p-toluenesulfonate (AdoMet) and $S$-adenosyl-L-homocysteine (AdoHcy) were generously donated by Dr. G. Stramentinoli (BioResearch Labs, Liscate, Italy). Amberlite CG-50 was from Accurate Chemical (Hicksville, New York) and Dowex 50W-X8 (200-400 mesh), from BioRad (Richmond, California). Other chemicals used in the study were of analytic grade quality.

\section{Animals}

Males of the mutant epileptic (SS) (epep) Peromyscus strain were obtained from stocks bred and maintained at our institute.

The wild-type, SR (EpEp) deermice were wildconceived animals obtained from the Museum of Zoology, University of Michigan, Ann Arbor, Michigan. The animals received "Teklan 4\% mouse and rat diet" and water ad libitum and were housed in stainless steel cages, 1-6/cage. The SS deermice were derived from homozygous matings (epep $\times$ epep) and were tested individually for clonic or tonic seizure response at least once after weaning by the key-jingling procedure of Barto (1956). They were compared to the wild-type Peromyscus which are generally SR at all ages (Barto, 1956; Doyle and Sellinger, 1980). All experiments were conducted on adult deermice, 70-90 days old. For intraventricular (i.vt.) $\left[{ }^{14} \mathrm{C}\right]$ putrescine or methionine injections, the mice were lightly anesthetized with ether, a small piece of scalp was 
removed for ease in identification of the injection site and putrescine $(0.5 \mu \mathrm{Ci})$ or methionine $(2 \mu \mathrm{Ci})$ was injected into the lateral cerebral ventricles in a vol. of $10 \mu \mathrm{l}$ of artificial cerebrospinal fluid (Merlis solution) (Schatz et al., 1978). Animals were sacrificed $1 \mathrm{~h}$ after i.vt. injection by immersion (head-first) into liquid nitrogen. Their brains were rapidly removed while still frozen and immediately immersed in liquid nitrogen after which they were stored at $-20^{\circ} \mathrm{C}$ until homogenization.

\section{Preparation of Brain Samples for Polyamine Determination}

For polyamine analysis, the frozen brains were homogenized in $5 \mathrm{vol}$. ( $\mathrm{w} / \mathrm{v})$ of $0.3 \mathrm{~m}$-perchloric acid and the homogenates centrifuged at $12.000 \times \mathrm{g}$ for $20 \mathrm{~min}$. The pellets were re-treated with $2 \mathrm{ml}$ of $0.3 \mathrm{M}$-perchloric acid and centrifuged as above. The pooled supernatants were adjusted to $\mathrm{pH} 7$ by the addition of $\mathrm{KOH}$ solution, allowed to stand at $4^{\circ} \mathrm{C}$ for $60 \mathrm{~min}$, and centrifuged as above to remove potassium perchlorate. The clear supernatants were lyophilized and the resulting dry powder was dissolved in $1 \mathrm{ml}$ of deionized water. In order to prepare UV absorbing derivatives of the polyamines, the samples were submitted to derivatization with benzoyl chloride as previously described for standard polyamine solutions (Redmond and Tseng, 1979).

\section{HPLC Separation of Polyamines}

Five to $50 \mu$ l of a methanol solution (original vol. 200 $\mu \mathrm{l})$ containing the benzoylated polyamines were injected onto the $\mu$ Bondapak $\mathrm{C} 18$ column and the polyamines eluted with $60 \%$ methanol (v/v) (flow rate, $2 \mathrm{ml} / \mathrm{min}$ ). The quantitative determination of the polyamines was carried out with the aid of calibration curves previously generated from standard solutions. Recoveries of the polyamines were determined by addition of [ ${ }^{14-}$ C]polyamines to brain homogenates followed by derivatization and HPLC analysis as above. We determined the amounts of radioactivity in the individual polyamines by collecting fractions $(1.0 \mathrm{ml})$ from the HPLC runs and counting them in $6 \mathrm{ml}$ of ACS (a tissue solubilizerscintillant mixture, Amersham/Searle, Arlington Heights, Illinois). With this technique, percent recoveries were found to be $61.3 \pm 2.4 \%$ for putrescine, $50.0 \pm 4.0 \%$ for spermidine, and $71.3 \pm 7.0 \%$ for spermine.

\section{Determination of $S$-Adenosyl-L-Methionine and $S$-Adenosyl-L-Homocysteine Levels and Specific Radioactivities}

Radioactive [8-14C]AdoHcy was prepared from Lhomocysteine and $\left[8-{ }^{14} \mathrm{C}\right]$ adenosine as previously described (Schatz et al., 1977a). The AdoHcy was purified by HPLC on a $\mu$ Bondapak C18 column. AdoHcy was eluted with $0.04 \mathrm{M}$-ammonium formate ( $10 \%$ methanol) (2 $\mathrm{ml} / \mathrm{min}$ ) after which the sample was lyophilized, dissolved in water and stored in small aliquots at $-80^{\circ} \mathrm{C}$ until use. AdoMet and AdoHcy levels were determined by a modified isotope-dilution method (Schatz and Sellinger, 1975; Schatz et al., 1977b; 1981b). To weighed frozen tissue samples were added $\left[{ }^{14} \mathrm{C}\right]$ AdoMet and AdoHcy $(1-7 \times$ $\left.10^{5} \mathrm{~d} . \mathrm{p} . \mathrm{m} . / \mu \mathrm{mol}\right)$ in a sufficient quantity to dilute the normal, endogenous tissue concentrations by about $40 \%$. The tissues were homogenized in $5 \mathrm{ml}$ of ice-cold 0.4 $M$-perchloric acid and centrifuged $(10,000 \mathrm{~g} \times 10 \mathrm{~min})$. The supernatants were adjusted to $\mathrm{pH} 5.5-6$ by stepwise addition of $\mathrm{KOH}(10 \mathrm{M}, 1 \mathrm{M}, 0.1 \mathrm{M})$ in an ice bath, and the volume was adjusted to $8 \mathrm{ml}$ with water. After centrifugation as above, the supernatant was divided into two $4 \mathrm{ml}$ fractions. For AdoMet determination, $4 \mathrm{ml}$ were applied to a Dowex-50 $\left(\mathrm{Na}^{+}\right)$column $(0.7 \times 3 \mathrm{~cm})$ previously equilibrated with $0.1 \mathrm{M}-\mathrm{NaCl}$. The column was washed successively with $15 \mathrm{ml}$ of $0.1 \mathrm{M}-\mathrm{NaCl}$ and $5 \mathrm{ml}$ of water, and AdoMet was eluted with $5 \mathrm{ml}$ of $6 \mathrm{M}-\mathrm{HCl}$. The $\mathrm{HCl}$ fraction was lyophilized and dissolved in $0.5 \mathrm{ml}$ of water, after which 25-50 $\mu$ l were injected onto a $\mu$ Bondapak C18 column. AdoMet was eluted with $0.04 \mathrm{M}$-monobasic ammonium phosphate ( $1 \%$ methanol) $(2 \mathrm{ml} / \mathrm{min})$. The AdoMet peak was collected and a $0.5 \mathrm{ml}$ aliquot counted in $5 \mathrm{ml}$ of ACS. Tissue concentrations of AdoMet were calculated with the isotope-dilution equation (Wang and Willis, 1965).

For AdoHcy determination, the remaining $4 \mathrm{ml}$ were applied to an Amberlite CG-50 $\left(\mathrm{H}^{+}\right)$column $(0.7 \times 3 \mathrm{~cm})$ previously equilibrated with water. The column was washed with $2 \mathrm{ml}$ of water followed by $15 \mathrm{ml}$ of $0.03 \mathrm{M}$ ammonium hydroxide, and AdoHcy was eluted with $5 \mathrm{ml}$ of $3 \mathrm{M}$-ammonium hydroxide. The AdoHcy fraction was lyophilized and dissolved in $0.5 \mathrm{ml}$ of water after which $100 \mu \mathrm{l}$ were injected onto a $\mu$ Bondapak C 18 column. AdoHcy was eluted with $0.04 \mathrm{M}$-monobasic ammonium phosphate ( $7.5 \%$ methanol) $(2 \mathrm{ml} / \mathrm{min})$. The rest of the experimental procedure was identical to that used for determination of AdoMet. This assay technique is capable of detecting as little as 10 pmol of AdoMet or AdoHcy. For determination of AdoMet and AdoHcy specific radioactivities (s.r.a.), mice received i.vt. injections of 2 $\mu \mathrm{Ci}$ of $\mathrm{L}-\left[1{ }^{14} \mathrm{C}\right]$ methionine and were sacrificed $\mathrm{I} \mathrm{h}$ later. AdoMet and AdoHcy were determined as described above, the only exception being the use of standard solutions of AdoMet and AdoHcy to aid in the determination of the tissue concentrations of AdoMet and AdoHcy.

\section{Determination of L-Methionine Levels and Specific Radioactivity}

L-Methionine was determined by the enzymatic procedure of Parrilla et al. (1973). The tRNA used in this procedure as a specific L-methionine acceptor was purified from 18-day old rat brains by the procedure of Ortwerth and Der (1974) as modified by Sellinger and Der (1980). After homogenization of the brains in $0.25 \mathrm{M}$-sucrose containing $35 \mathrm{~mm}$-Tris- $\mathrm{HCl}$ (pH 7.4), $25 \mathrm{~mm}-\mathrm{KCl}, 25$ mM- $\mathrm{MgCl}_{2}, 1 \mathrm{~mm}$-sodium EDTA, $10 \mathrm{~mm}$-2-mercaptoethanol and $0.05 \%$ diethylpyrocarbonate, the homogenates were centrifuged $(30,000 \times g$ for $20 \mathrm{~min})$, and the tRNA was extracted from the supernatants by phenolization followed by further purification by DEAEcellulose chromatography (Sellinger and Der, 1980). Methionine determinations were carried out on the water washes from the Amberlite CG-50 columns (see above). These fractions were lyophilized, redissolved in $0.5 \mathrm{ml}$ of water and 50-100 $\mu$ l were added to the tRNA aminoacyla- 
tion reaction mixtures. These fractions contained 95-98\% of the radiolabeled methionine applied to the Amberlite columns (data not shown). The aminoacyl tRNA synthetases were prepared from rat liver as described above (Sellinger and Der, 1980). The aminoacylation of IRNA with standard solutions of methionine or tissue extracts was carried out in the presence of optimal concentrations of $\mathrm{KCl}(10 \mathrm{mM})$. magnesium acetate (10 $\mathrm{mM}), 0.4 \mathrm{~A}_{266}$ units of (RNA, $1 \mu \mathrm{Ci}$ of $\mathrm{L}-\left[{ }^{3} \mathrm{H}\right]$ methionine and $1 \mathrm{mg}$ of aminoacyl tRNA synthetase protein. The reaction mixtures were incubated for $10 \mathrm{~min}$ at $37^{\circ} \mathrm{C}$ after which the reaction was stopped by the addition of $5 \mathrm{ml}$ of $10 \%$ trichloroacetic acid (TCA). The resultant mixture was filtered through Whatman GF/A filters, and the filters were rinsed twice with $5 \mathrm{ml}$ of $10 \%$ TCA, twice with $10 \mathrm{ml}$ of $5 \%$ TCA and once with $10 \mathrm{ml}$ of ether-ethanol $(1: 2$, $v / v)$. The filters were air-dried and counted in $5 \mathrm{ml}$ of ACS. Methionine concentrations were calculated with the aid of a standard curve that was run concurrently with the tissue samples.

For determination of methionine s.r.a., mice received i.vt. injections of $\mathrm{L}-\left[1{ }^{14} \mathrm{C}\right]$ methionine as described under AdoMet and AdoHcy determination (see above). An aliquot $(20 \mu \mathrm{l})$ of tissue sample (Amberlite CG-50 water wash) as used for methionine determination (see above) was spotted on silica gel TLC plates together with nonradioactive carrier amounts of methionine, methionine sulfoxide, L-cysteine, L-homocysteine and cystathionine ( $5 \mu$ l of a solution containing $1 \mathrm{mg} / \mathrm{ml}$ of each amino acid). The TLC plates were developed in phenol-water $(80: 20$, $w / v)$, after which the amino acids were identified with ninhydrin spray. The methionine spot was scraped from the TLC plate, placed in a scintillation vial containing 1 $\mathrm{ml}$ of water and shaken for $60 \mathrm{~min}$ at $60^{\circ} \mathrm{C}$. After addition of $10 \mathrm{ml}$ of $A C S$, the sample was counted and the radioactivity contained therein was used for determination of methionine s.r.a.

\section{RESULTS}

\section{Brain Polyamine Levels in SR and SS Deermice}

The application of the HPLC method of Redmond and Tseng (1979) to the separation and quantitative determination of benzoylated polyamines in brain tissue readily allowed the measurement of $\mathrm{Pt}, \mathrm{Spd}$ and Spm levels in individual brains. Since adult rodent brain Pt levels are much lower than those of Spd or Spm (Seiler and Lamberty, 1975; Pajunen et al., 1979), our procedure requires approximately 50 $\mathrm{mg}$ of brain tissue for $\mathrm{Pt}$ determinations as compared to 2-2.5 mg for Spd or Spm. The additional modifications of increasing the methanol concentration to $60 \%(v / v)$ and using a $\mu$ Bondapak C18 column (rather than a Brownlee RP-8 column) allowed an appreciable shortening of the total elution time for all three polyamines from about 15 to 10 min. Figure 1 illustrates the separation of the endogenous polyamines and their radioactivity profile after a $1 \mathrm{~h}$ (i.vt.) pulse of $\left[{ }^{4} \mathrm{C}\right]$ putrescine to SS animals. There is a significant amount of radioac-

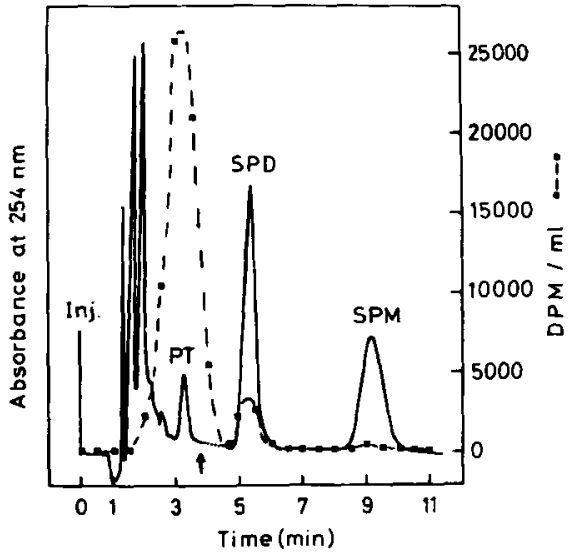

FIG. 1. HPLC elution profile of benzoylated polyamines in SS deermouse brain. Mice received i.vt. injections of $0.5 \mu \mathrm{Ci}$ of ${ }^{14} \mathrm{C}$ putrescine in $10 \mu \mathrm{l}$ of artificial cerebrospinal fluid and were sacrificed $1 \mathrm{~h}$ later. Polyamines were analyzed as described in Materials and Methods. The arrow indicates a change in recorder sensitivity from 0.05 to 0.2 absorbance units, full scale. $1 \mathrm{ml}$ fractions were collected for determination of specific radioactivity. PT, putrescine; SPD, spermidine; SPM, spermine.

tivity in both the Pt and Spd fractions but not in the Spm fraction (Fig. 1; see below).

As in the brain of the albino mouse (Mus) and that of the rat (Shaw and Pateman, 1973; Snyder et al., 1973; Harik and Snyder, 1974; Seiler and Lamberty, 1975; Seiler and Schmidt-Glenewinkel, 1975; Pajunen et al., 1979), the levels of Pt in deermouse brain were significantly lower than those of Spm (Table 1). Spm levels were, in turn, moderately lower than levels of Spd. There were no significant differences in polyamine steady state levels in brains of SR and SS deermice.

\section{Brain Polyamine Formation in SR and SS Deermice}

Following a $1 \mathrm{~h}$ i.vt. pulse of either $\mathrm{L}-\left[{ }^{14} \mathrm{C}\right.$ -

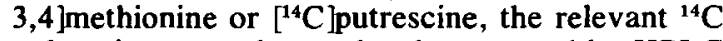
polyamines were benzoylated, separated by HPLC and their s.r.a. values determined. As previously noted (Snyder et al., 1973; Shaw, 1979b), a 1 h pulse of $\left[{ }^{4} \mathrm{C}\right]$ putrescine yielded no radioactivity in the Spm fraction (Table 2). Conversely, the s.r.a. of the Spm fraction was higher than that of the Spd fraction in both the SR and SS brains following a [14Clmethionine pulse (Table 2).

Of particular interest is the significantly lower Spd s.r.a. value after $\left[{ }^{4} \mathrm{C}\right]$ putrescine in SS compared to SR brains. This value was generated in the face of identical SS and SR Pt s.r.a. values (Table 2) and reveals SR-SS differences in the labeling of the Pt-derived, but not of the methionine-derived, moiety of Spd. This finding complements those of 
TABLE 1. Brain polyamines in SR and SS deermice

\begin{tabular}{cccc}
\hline Animal & Putrescine & Spermidine & Spermine \\
\hline SR & $8.19 \pm 1.19(12)$ & $240.2 \pm 22.4(12)$ & $123.3 \pm 12.8(12)$ \\
SS & $7.35 \pm 1.19(11)$ & $253.0 \pm 22.4(11)$ & $126.7 \pm 14.0(10)$ \\
\hline
\end{tabular}

Values are expressed in $\mathrm{nmol} / \mathrm{g}$ as means \pm S.E.M. Numbers in parentheses represent the number of animals in each experimental group.

Antrup and Seiler (1980), who examined the longterm turnover of polyamines in mouse brain.

\section{Brain Levels and Specific Activities of Methionine, AdoMet and AdoHcy in SR and SS Deermice}

Before determining the rate of conversion of methionine to AdoMet and of AdoMet to the polyamines, it was necessary to compare the endogenous levels of methionine, AdoMet, and AdoHcy in the SS and SR deermouse brains. Figure 2A shows that brains of SS deermice have significantly higher levels of methionine and lower levels of AdoMet compared to their seizure-resistant counterparts (SR). There were no significant differences in brain AdoHcy levels between SR and SS mice.

We also determined the specific radioactivity of $\left[{ }^{14} \mathrm{C}\right]$ methionine, $\left[{ }^{14} \mathrm{C}\right]$ AdoMet, and $\left[{ }^{14} \mathrm{C}\right]$ Ado Hcy following a $1 \mathrm{~h}$ i.vt. pulse of $\mathrm{L}-\left[1-{ }^{14} \mathrm{C}\right]$ methionine. This enabled us to estimate the flux of methionine through the transmethylation pathway in the absence of any spillover of radioactivity into the polyamine pathway. Under these conditions, the SS brains had significantly lower methionine s.r.a. values and significantly higher AdoMet s.r.a. values than the SR brains, while there were no differences in AdoHcy s.r.a. values (Fig. 2B). These findings suggest differences in rate of flux of cerebral methionine into AdoMet between SR and SS deermice which could not be accounted for by the observed differences in endogenous pools of brain methionine or AdoMet in these two groups of animals (Fig. 2A).

\section{Acoustic Stimulation of SS Deermice}

Acoustic stimulation of the SS animals led to circular running behavior within $45 \mathrm{~s}$. If allowed to proceed, such behavior invariably terminated in tonic seizures. Animals were, therefore, killed as soon as running behavior was observed. Table 3 shows higher Spd values in the brains of the stimulated deermice (compare to Table 1, SS Spd value). Also, the s.r.a. value of Spd was no longer significantly different from the nonstimulated SS Spd s.r.a. value (Table 2 ) or, for that matter, from the SR Spd s.r.a. value.

\section{DISCUSSION}

The HPLC procedure (Redmond and Tseng, 1979) adapted for the separation and quantitation of brain polyamines exceeds all existing procedures in brevity and simplicity since it involves: (1) the direct benzoylation of a neutralized perchloric acid supernatant of brain; (2) its ether extraction and evaporation of the ether under nitrogen; and (3) the injection of the redissolved sample directly onto the HPLC column. Elution with $60 \%$ methanol as the only mobile phase clearly separated all three benzoylated polyamines from each other, within 10-11 min. HPLC of 5-dimethylaminonaphthalene-1sulfonyl (dansyl) derivatives of polyamines on a $\mu$ Bondapak C18 column (as used in this study) was recently reported to require a programmed gradient elution system of 1-heptanesulfonic acid and acetonitrile and an elution time of $\mathbf{3 0} \mathrm{min}$ (Brown et al., 1979). In another study a 40 min elution time was required to separate dansylated polyamines by

TABLE 2. The conversion of $\left.L-\gamma^{14} C\right]$ methionine and $\left[{ }^{14} C\right]$ putrescine to ${ }^{14} C$ polyamines in brains of $S R$ and $S S$ deermice

\begin{tabular}{ccccc}
\hline & & \multicolumn{3}{c}{${ }^{14} \mathrm{C}$ polyamine (d.p.m./nmol) } \\
\cline { 3 - 5 } Animal & ${ }^{14} \mathrm{C}$ precursor & Putrescine & Spermidine & Spermine \\
\hline SR & {$\left[{ }^{44} \mathrm{C}\right] \mathrm{Met}$} & - & $21.2 \pm 1.0(5)$ & $26.9 \pm 2.3(5)$ \\
& {$\left[{ }^{14} \mathrm{C}\right] \mathrm{Pt}$} & $93.7 \pm 7.0(7)$ & $819.3 \pm 68.6(7)$ & N.D. \\
SS & {$\left[{ }^{44} \mathrm{C}\right] \mathrm{Met}$} & - & $18.4 \pm 2.3(5)$ & $23.0 \pm 3.8(5)$ \\
& {$\left[{ }^{4} \mathrm{C}\right] \mathrm{Pt}$} & $86.7 \pm 5.3(5)$ & $614.5 \pm 42.8(5)^{a}$ & N.D. \\
\hline
\end{tabular}

Mice were given an i.vt. injection of either $\mathrm{L}-\left[3,4^{14} \mathrm{C}\right.$ methionine $(2 \mu \mathrm{Ci})$ or $\left[{ }^{14} \mathrm{C}\right.$ putrescine $(0.5 \mu \mathrm{Ci})$ and killed $1 \mathrm{~h}$ later. Values are expressed in d.p.m./nmol as means \pm S.E.M. Numbers in parentheses represent the number of animals in each experimental group.

N.D.: No radioactivity was detected in this fraction.

a Significantly different from SR value, $p<0.05$ (Student's $t$-test). 
HPLC with a Lichrosorb RP-8 column and programmed gradient elution system consisting of methanol-water (Seiler et al., 1978). Elution time could be reduced to $20 \mathrm{~min}$ if the dansylated polyamines were separated by HPLC on a Micropak $\mathrm{CN}-10$ column with an elution gradient of acetonitrile-water (Saeki et al., 1978). Other, more cumbersome procedures, require prepurification of the biological samples (Kai et al., 1979) or, alternatively, dansylation followed by elution from a Micropak $\mathrm{CN}-10$ column with a discontinuous gradient (Newton and Abdel-Monem, 1977).

The deermice used in this study were of interest because the SS animals represent a unique example of an autosomal recessive mutant endowed with an innate susceptibility to convulse when stimulated audiogenically by the sound of jingling keys (Barto, 1956). We have shown previously that the activity of cerebral histamine $N$-methyltransferase in SS deermice and SS DBA/2J mice (21 days old) was lower than that of SR deermice as well as SR DBA/2J mice (70 days old) (Doyle and Sellinger, 1980). We have also reported higher initial in vivo rates of methylation of $\left[{ }^{3} \mathrm{H}\right]$ histamine to $\left[{ }^{3} \mathrm{H}\right]$ methylhistamine in brains of the SS compared to the SR deermice (Doyle et al., 1981). This finding was in agreement with our previous observation of increased brain histamine methylation following administration of MSO to Swiss-Webster mice (Mus mus) (Schatz et al., 1978). The present results reveal two additional similarities between SS deermice and MSO-treated Mus, namely, decreased brain AdoMet levels (Fig. 2A) and increased AdoMet S.r.a. values (Fig. 2B) (when compared to SR deermice or saline-treated $M u s$, respectively) following i.vt. $\left[{ }^{4} \mathrm{C}\right]$ methionine. Analysis of the flux of $\left[{ }^{14} \mathrm{C}\right]$ methionine (via AdoMet) into polyamines, however, showed dissimilarities between SS deermice and MSO-treated mice in that the s.r.a. values for Spd and Spm were the same in brains of SS and SR deermice (Table 1) but were significantly increased in brains of MSO-treated mice compared to saline controls (Porta et al., 1981). Of further interest are the findings concerning the conversion of $\left[{ }^{4} \mathrm{C}\right] \mathrm{Pt}$ to $\left[{ }^{4} \mathrm{C}\right] \mathrm{Spd}$. This process appeared somewhat slowed in the brains of SS, relative to SR, deermice (Table 2), while remaining unaltered in brains of MSO-treated, compared to saline-treated mice (Porta et al., 1981). It is thus possible to conclude that the SS condition, whether genetically determined (as in SS deermice) or chemically elicited (as in MSO-treatment), correlates positively with higher than normal rates of conversion of exogenous methionine to brain AdoMet and leads to an enhanced rate of utilization of AdoMet via the transmethylation pathway. The role of brain AdoMet as a polyamine precursor, in contrast, appears to be altered only in the brains of MSOtreated mice but not in those of SS deermice (Table 2; Porta et al., 1981).

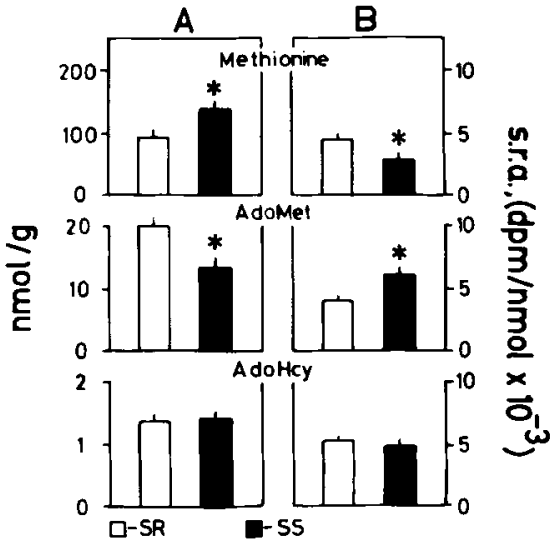

FIG. 2. Brain levels and specific radioactivities of $L$ methionine, $S$-adenosyl-L-methionine and $S$-adenosyl-Lhomocysteine in SR and SS deermice. Values in panel (A) are expressed in $\mathrm{nmol} / \mathrm{g}$ as means \pm S.E.M. in 6-7 mice. Values in panel (B) are expressed in d.p.m./nmol as means \pm S.E.M. in 6-7 mice. For s.r.a. determinations (panel B) mice received i.vt. injections of $L-\left[1-{ }^{14} \mathrm{C}\right]$ methionine $(2 \mu \mathrm{Ci})$ and were killed 1 h later. "Significantly different from SR mice; $p<0.05$ (Student's $t$-test).

One interpretation of this finding may be that changes in the flux of AdoMet toward the npropylamino moiety of Spd and Spm represent a secondary response to the epileptogenic stimulus, i.e. this pathway becomes activated only after the convulsant agent (MSO) or the acoustic stimulus has triggered the primary response, which consists of an accelerated AdoMet synthesis and utilization for transmethylation reactions. Preliminary, albeit indirect, support for such a possibility is shown in Table 3. As may be noted, acoustically stimulated SS deermice, killed immediately prior to seizures, had statistically significantly higher brain spermidine levels and, by extension, an increased total polyamine content. There was also a corresponding, although not statistically significant, increase in

TABLE 3. Effect of acoustic stimulation on brain polyamine levels and specific radioactivity in $S S$ deermice

\begin{tabular}{lcc}
\hline Polyamine & nmol/g & d.p.m./nmol \\
\hline Putrescine & $9.86 \pm 1.02(5)$ & $80.5 \pm 5.9(5)$ \\
Spermidine & $324.1 \pm 24.2(5)^{a}$ & $764.8 \pm 75.7(5)^{b}$ \\
Spermine & $153.3 \pm 14.2(5)$ & N.D. \\
\hline
\end{tabular}

SS deermice were given an i.vt. injection of $\left[{ }^{14} \mathrm{C}\right]$ putrescine $(0.5 \mu \mathrm{Ci})$ and sacrificed $1 \mathrm{~h}$ later. Values are expressed either in $\mathrm{nmol} / \mathrm{g}$ or d.p.m./nmol as mean \pm S.E.M. Number in parentheses represents the number of experimental animals in each group. Acoustic stimulation was by the key jingling method of Barto (1956). N.D., No radioactivity detected.

a Significantly different from SS value in Table $1 ; p<0.05$ (Student's $t$ test).

b This value is not significantly different from that shown for SR deermice in Table 2; $p>0.05$. 
the s.r.a. value of Spd, suggesting a sudden acceleration of the synthesis of Spd from Pt in response to acoustic stimulation. It is important to note that acoustic stimulation of SR animals resulted in no alterations of brain polyamine levels or s.r.a. values (data not shown).

\section{ACKNOWLEDGMENT}

This work was supported by U.S. Public Health Service grant NINCDS 06294 to OZS.

\section{REFERENCES}

Anderson D. J., Crossland J., and Shaw G. G. (1975) The actions of spermidine and spermine on the central nervous system. Neuropharmacology 14, 571-577.

Antrup H. and Seiler N. (1980) On the turnover of polyamines spermidine and spermine in mouse brain and other organs. Neurochem. Res. 5, 123-143.

Barto E. (1956) Tests for independence of "waltzer" and "ep" sonogenic convulsions from certain other genes in the deermouse Peromyscus maniculatus. Contrib. Lab. Vertebr. Biol. Univ. Mich. 74, 1-15.

Brown, N. D., Sweet R. B., Kintzios J. A., Cox D. H., and Doctor B. P. (1979) Determination of 5-dimethylaminonaphthalene-1-sulfonyl derivatives of urinary polyamines by ion-pair high-performance liquid chromatography. $J$. Chromatogr. 164, 35-40.

Dainat J., Salas C. E., and Sellinger O. Z. (1978) Alterations of the specificity of brain IRNA methyltransferases and of the pattern of brain tRNA methylation in vivo by methionine sulfoximine. Biochem. Pharmacol. 27, 2655-2658.

Doyle R. L. and Sellinger O. Z. (1980) Differences in activity in cerebral methyltransferases and monoamine oxidases between audiogenic seizure susceptible and resistant mice and deermice. Pharmacol. Biochem. Behav. 13, 589-591.

Doyle R. L., Schatz R. A., and Sellinger O. Z. (1981) Differences in the methylation of brain histamine in vivo between audiogenic seizure-sensitive and -resistant deermice. Life Sci, 28, 2805-2810.

Dresser H., Lutz D., Krieger O., and Stierer M. (1980) Rapid detection of polyamines in the sera of patients with colorectal carcinoma by liquid ion-exchange chromatography. Oncology 37, 376-380.

Harik S. I. and Snyder S. H. (1974) Putrescine: regional distribution in the nervous system of the rat and cat. Brain Res. 66, 328-331

Kai M., Ogata T., Haraguchi K., and Ohkura Y. (1979) Highperformance liquid chromatographic determination of free and total polyamines in human serum as fluorescamine derivatives. J. Chromatogr. 163, 151-160.

Newton N. E. and Abdel-Monem M. M. (1977) Inhibitors of polyamine biosynthesis. 4. Effects of -methyl-( \pm -omithine and methylglyoxal bis(guanylhydrazone) on growth and polyamine content of $\mathrm{L} 1210$ leukemic cells of mice. J. Med. Chem. 29, 249-253.

Ortwerth B. J. and Chu-Der O. M. Y. (1974) Studies on the specialized transfer RNA population of the lens. Exp. Eye Res. $19,521-532$.

Pajunen A. E. I., Hietala O. A., Baruch-Virransalo E.-L., and Piha R. S. (1979) The effect of D,L-allylglycine on polyamine and GABA metabolism in mouse brain. J. Neurochem. 32, $1401-1408$

Parrilla R., Ayuso-Parrilla M. S., and Goodman M. N. (1973) Determination of some $L$-amino acids in biological samples by aminoacylation of tRNA. Anal. Biochem. 54, 362-369.

Porta R., Schatz R. A., and Sellinger O. Z. (1981) The modulation of brain methylation affects brain polyamine biosynthesis. Trans. Am. Soc. Neurochem. 12, 150.
Radhakrishnan A. N., Stein S., Licht A., Gruber K. A., and Udenfriend S. (1977) High-efficiency cation-exchange chromatography of polypeptides and polyamines in the nanomole range. $J$. Chromatogr. 132, 552-555.

Redmond J. W. and Tseng A. (1979) High-pressure liquid chromatographic determination of putrescine, cadaverine, spermidine and spermine. J. Chromatogr. 170, 479-481.

Saeki Y., Uehara N., and Shirakawa S. (1978) Sensitive fluorometric method for the determination of putrescine, spermidine and spermine by high-performance liquid chromatography and its application to human blood. J. Chromatogr. 145, 221-229.

Sakurada T., Onodera K., Tadano T., and Kisara K. (1975) Effects of polyamines on the central nervous system. Jpn. J. Pharmacol. 25, 653-661.

Salas C. E., Ohlsson W. G., and Sellinger O. Z. (1977) The stimulation of cerebral $N^{2}$-methyl and $N_{2}^{2}$-dimethyl guanine-specific tRNA methyltransferases by methionine sulfoximine: an in vivo study. Biochem. Biophys. Res. Commun. 76, 1107-1115.

Schatz R. A. and Sellinger O. Z. (1975) Effect of methionine and methionine sulfoximine on rat brain $S$-adenosylmethionine levels. $J$. Neurochem. 24, 63-66.

Schatz R. A., Vunnam C. R., and Sellinger O. Z. (1977a) Species and tissue differences in the catabolism of $S$-adenosyl-L. homocysteine: a quantitative study. Life Sci. 20, 375-384.

Schatz R. A., Vunnam C. R., and Sellinger O. Z. (1977b) Sadenosyl-L-homocysteine in brain: regional concentrations, catabolism and the effects of methionine sulfoximine. Neurochem. Res. 2, 27-34.

Schatz R. A., Frye K., and Sellinger O. Z. (1978) Increased in vivo methylation of $\left[{ }^{3} \mathrm{H}\right]$ histamine in the methionine sulfoximine epileptogenic mouse brain. J. Pharmacol. Exp. Ther. 207, 794-800.

Schatz R. A., Wilens T. E., and Sellinger O. Z. (1981a) The elevation of brain $S$-adenosylhomocysteine in vivo counteracts the MSO-induced increase in phospholipid and protein carboxymethylation. Trans. Am. Soc. Neurochem. 12, 151.

Schatz R. A., Wilens T. E., and Sellinger O. Z. (1981b) Decreased transmethylation of biogenic amines after in vivo elevation of brain $S$-adenosyl-L-homocysteine. $J$. Neurochem. 36, 1739-1748.

Seiler N. (1977) Assay procedures for polyamines in urine, serum and cerebrospinal fluid. Clin. Chem. 23, 1519-1526.

Seiler N. and Lamberty U. (1975) Interrelations between polyamines and nucleic acids: changes of polyamines and nucleic acid concentrations in the developing rat brain. $J$. Neurochem. 24, 5-13.

Seiler N. and Schmidt-Glenewinkel T. (1975) Regional distribution of putrescine, spermidine and spermine in relation to the distribution of RNA and DNA in the rat nervous system. J. Neurochem. 24, 791-795.

Seiler N., Knogden B., and Eisenbeiss F. (1978) Determination of di- and polyamines by high-performance liquid chromatographic separation of their 5-dimethyl aminonaphthalene-1sulfonyl derivatives. J. Chromatogr. 145, 29-39.

Sellinger $O$. Z. and Der $O$. (1980) The biosynthesis of transfer ribonucleic acid in the developing rat brain and in cultured glial cells. $J$. Neurochem. 35, 1436-1445.

Shaw G. G. (1979a) The polyamines in the central nervous system. Biochem. Pharmacol. 28, 1-6.

Shaw G. G. $(1979 b)$ The synthesis and turnover of spermidine and spermine in mouse brain. Neurochem. Res. 4, 269-275.

Shaw G. G. and Pateman A. J. (1973) The regional distribution of the polyamines spermidine and spermine in brain. $J$. Neurochem. 20, 1225-1230.

Snyder S. H., Shaskan E. G., and Harik S. I. (1973) Polyamine disposition in the central nervous system, in Polyamines in Normal and Neoplastic Growth (Russell D. H., ed), pp. 199-213. Raven Press, New York.

Wang C. H. and Willis D. L. (1965) Radiotracer Methodology in Biological Science. pp. 360-363. Prentice Hall, Englewood Cliffs, New Jersey. 